\title{
Teaching methods for increasing the participations of students: Innovative dynamics games
}

\author{
Ester Oliveras, Patrícia Crespo \\ ${ }^{1}$ Universitat Pompeu Fabra (Spain) \\ ester.oliveras@upf.edu,patricia.crespo@upf.edu
}

Received: June 2013

Accepted: July 2013

\section{Abstract}

Purpose: This paper analyses new dynamics as teaching methodologies in the context of the degrees adapted to the EHEA. The aim of this study is double: to assess whether there is greater involvement in seminars with these new dynamics and to test if learning also experienced changes.

Design/methodology/approach: To experiment with the introduction of innovative dynamic games in an introductory course in accounting. These new dynamics are applied during the academic year 2010-11 in the UPF. The design, implementation and evaluation of the methodology devised have followed three stages: 1) Game Design and adequate dynamic; 2) To test the games; 2) Implementation during the course.

Findings: The results show that students value positively those dynamics improving their learning and creating greater involvement.

Research limitations/implications: There are some contradictory results regarding the knowledge gained by the students. Another area to be explored relates to the skills that the teacher must have in order to manage this type of dynamics.

Originality/value: In an introductory level of the Financial Accounting course the most common dynamics is solving exercises. Due to the nature of matter, these are closed so they not provoke discussion among students. However, you can use activities that allow greater participation, especially through dynamics or games. This paper shows that.

Keywords: dynamic games, learning, participation

JEL Codes: A23, M41 


\section{Introduction}

The new approach to university teaching is moving towards a student-centered methodology. Under this new framework, both student and teacher, change their traditional roles. The student becomes a more active and responsible player in the learning process. For example, to receive more frequent feedback of results through continuous assessment, the student can better monitor the level of dedication to the subject. The teacher should use more teaching strategies to accommodate different forms of student learning (Anderson \& Adams, 1992).

Previous studies show that the most active students in classes, aside from learning more enjoyable, achieve better academic results (Stegemann \& Sutton-Brady, 2010). With the introduction of new teaching methods and the use of a continuous evaluation system, it has been proven that there are a higher rate of students taking the final exam and a lower abandonment of the subject (Tejada Ponce, Pérez Morote, Ramírez Córcoles, Tejedo Romero \& Pontones Rosa, 2012). Teachers often seek methods to increase the involvement and participation of students in class. Along these lines, Cohen (1991) states that the biggest challenge for teachers is to find ways in which students participate and thus ensure passive ones favorable results of learning. Graeml, Baena and Mihai Yiannaki (2010) describe different actions carried out through a business simulation. The activity facilitated that students moved from having a passive and often unmotivated behavior to engage in classroom activities and post-seminars analysis. In the same line, Cladellas, Castelló, Badia \& Cirera (2013) show how the use of powerpoint can lead to poorer results in comparison to the use of the traditional blackboard. A possible explanation is that students make less effort to understand the masterclass, trusting on the available digital material.

The game is an inherently human activity. As children, all people have learned to relate to our physical and social environment through play. The game has implied a fun feature that reduces tension and predisposes to learning. Games are used in an educational way in many schools, but dropped dramatically to reach higher education. In some areas, like medicine or nursing, simulation of reality is used during the studies to gain confidence (Sinclair \& Ferguson 2009) In the area of business, there are some examples because Games Business and Investment Games in the Stock Exchange are frequent. These materials usually enjoy wide acceptance among students. Rodriguez Jiménez, Terrón \& Gracia (2010) presented a project development and evaluation of generic skills through a program of bodywork, creative movement and nonverbal communication. The preliminary results of its implementation in different grade students make an outstanding satisfaction. Gomez-Ruiz and Naranjo-Gil (2011), present a group work activity and a proposal evaluation matrix of this activity. They related indicators measuring the success of teamwork: effectiveness, efficiency, attitude toward the group and troubleshooting. The overall objective is to improve the ability of the student group work. 
The introduction of dynamic games or broader exercises than the traditional ones allows for greater student participation (Pozo \& Perez Echevarría, 2009). In these dynamics, the student feels less pressure and allowed to learn through discussion with peers and the method of trial and error. Another consideration to keep in mind is that students who are coming to higher education have grown up with multimedia resources and access to a wealth of information. They are accustomed to receiving a high degree of information daily, so keep the focus on the traditional format for them is more difficult.

\section{Methodology}

This article presents the results of experiment with the introduction of innovative dynamic games in an introductory course in accounting. In this, the most common dynamic is to solve exercises. Due to the nature of the subject the exercises are closed and well defined so no discussion among students is provoked. Despite these limitations, it is possible to introduce activities that allow for greater student participation, especially through gaming dynamics or broader than traditional exercises. The design, implementation and evaluation of the methodology devised have followed the stages outlined below:

\section{Phase 1. Game design and adequate dynamic}

In the first phase, dynamics were designed with the advice of an expert in games. The objectives were, first engage the student and then, participate using the contents explained in class. This is done using a system of competition between different groups of students. The end result was little "puzzles" or "enigmas" involving the active participation and integrated knowledge of previous concepts in order to be solved. These games had a variable duration of 10 minutes to 1 hour and its complexity was increasing over the course.

We identified two types of games:

a) Resolution of basic exercises

Being an introductory course, there are many short exercises to practice and consolidate the knowledge acquired. These games are solved with these more creative methods: competition, body movement, puzzles, games with clues, etc.

b) Simulated reality

Once students achieved all the contents of the course, they should be able to do, produce and record various accounting operations and make the year end. This is a common procedure for all companies. The most complete game was designed simulating this mechanism in a simplified way but funny and with competition. 
The materials of the games (files, puzzle, etc.), were accompanied by a very detailed application guide that describes the educational goal of the game, the estimated time it takes to develop, what material is needed the minimum and maximum number of students who can participate and the slogans that the teacher must give for the proper functioning of the activity.

This guide is designed for any teacher in the area who is interested in implementing it. Following this guide they will have all the necessary information to develop the games. Below are some examples.

Example 1: Resolution of basic exercises

Objective of the game: Integrate the order of items in the Balance sheet.

Material:

- Balance sheet cards (30 cards) + some Profit and Loss account card trap (24 cards).

- A clock to control time.

Estimated time: 20 ximum number of students: 32

Needs of the area: Open room. No chairs or removed to the sides.

\section{Previous preparation of students:}

Study the structure of the Balance sheet (Item 2 of the syllabus. The Balance sheet).

Review some Balance sheet exercises (eg, Exercise 2.6. of the syllabus "Transports Maresme").

\section{Give directions to students:}

"Then we will distribute some cards. At the moment not see them" (Hand out one card per student)

"Each of you has an accounting item targeted at the card. When I directed you can flip the card and have 3 minutes to order as the Balance sheet. You can also talk one each other.

Ready? One, two, three and now! "

Once they believe they are well placed the teacher reviews and gives as valid or correct them.

Students return the cards.

"Now we will distribute the cards again and you have to order in 3 minutes. To make it more exciting, now you can not show or talk the concept you have in the card. You can talk but not directly say the word or concept of the same family. Let's see an example " 
The teacher shows a card with some concept and asks students how they could do to define it.

Cards are distributed again.

"Ready? One, two, three and now! "

Once they believe they are well placed the teacher reviews and gives as valid or correct them.

\section{Closure:}

- Anyone who has played some concept did not know?

- Summarize the basic criteria for sorting according to enforceability (Equity+ Liabilities) and liquidity (Assets).

\section{Example 2: Resolution of basic exercises}

Objective of the game: Understanding the relationship between the Balance sheet and Income statement.

\section{Material:}

- 3 to 4 sheets of paper with the basic structure of balance sheet and income statement.

- 4 cards with clues.

- A clock to control time.

Estimated time: 30 minutes.

Maximum number of students: 20

Needs of the area: Chairs or not. Central table to write or on the ground.

\section{Previous preparation of students:}

Study the relationship between Balance sheet and Income statement (Item 3 of the syllabus. Accounting methods).

Review some exercises (eg, Exercise 3.1. of the syllabus "Albert Pons" and 3.2. "Jaume Comas").

\section{Give directions to students:}

"We need to make 4 teams of 5 people". 
"Then you will spread sheets of paper with the basic structure of balance sheet and income statement. This is your working paper. You need something to write. "

"We also deal a card that contains 10 clues. You should find two amounts:

- Whether the company has profit or loss and for what amount?

- What is the total amount of assets? And the net assets and liabilities"

Ready? One, two, three and now! "

As the teams finished, they are asked to be in silent until all teams have found the final solution. Alternatively, they can observe silently the other groups.

There are only two exercises, so both teams will do the same exercise.

\section{Closure:}

- Ask each person has learned something new.

- Or if they have been able to practice on knowledge they already ha

\section{Example 3: Simulated reality}

\section{Initial situation}

Students formed five groups. Each group is placed somewhere in the room. It is important that the groups have some element that identifies them easily, so there will hang a sign that is visible to all.

\section{Dynamics of the game. Summary}

The game shows an accounting year. It is developed in five phases. Each is a time of the accounting year. In each phase participants will receive an envelope with the information they need to give and receive and to be counted. Each phase will last 15 minutes.

The first phase will make the closing of the previous year and will require information to be processed and give a specific number.

The second phase will live the first six months of the year. In this case, each group must relate to one another, buy and sell products and record these movements in his book daily. Every time a group of players move towards another group will receive an invoice.

The third phase is equal to the second.

The fourth stage is the last. Players need to close the accounting year and give answers to some unexpected events which occurred. 


\section{Phase 2. To test the games}

In the second phase, the dynamics were tested in sessions specially designed for this, outside the ordinary course of teaching the subject.

The objectives of this phase were several:

- Check the instructions provided to students.

- Observe the students' ability to solve the games.

- Observe the attitude of students, especially activity vs. passivity.

- Collect the views of students.

In the test phase, the recipients were students who did not pass the Introduction to Financial Accounting course taught at the 2nd ECO / ADE first quarter of 2009-10 academic year. Given the 4 groups of Introduction to Financial Accounting, a total of 30 students didn't pass, 4 didn't present at the final exam and 5 cancelled the call.

We contacted the 30 students that didn't pass, first by mail and then directly, which is what actually worked best. The maximum number of students in the experiment was set at 20 . Finally, signed up 17 students. However 4 did not come to any meeting.

The decision about the dates to conduct the sessions was complicated. We though that in early September we will have few assistance. Finally, we chose to do it in the middle of June, despite the drawbacks that students had completed the course six months ago and were just starting the exams of the subjects in the third quarter. Additionally, learning obtained by these sessions did not have effect until September, when they take the recovering exam. To counter these drawbacks we gave an incentive of 0.5 points on the final examination under the consent of the four groups of teachers who had taught this course.

The opinions of students are reported in table 1 . They answer a short questionnaire. The experience was valued highly.

\begin{tabular}{|l|c|c|}
\hline \multicolumn{1}{|c|}{ Results } & Mean & Mode \\
\hline The experience was positive & 4,64 & 5 \\
\hline It has helped me to learn new concepts & 3,73 & 4 \\
\hline It has helped me to freshen up contents & 4,82 & 5 \\
\hline It has helped me to consolidate contents & 3,73 & 4 \\
\hline It has helped me to go over the contents & 4,36 & 4 \\
\hline
\end{tabular}

Note: We used a 1-5 scale, 1 indicates disagreement, 5 indicating. Agreement.

Table 1. Evaluation of the test phase 
During the sessions we noted that all students had an active role, students with less knowledge, made questions and relied on the best prepared students who assumed the leadership role. There were no cases of completely passive students.

Some students' comments were as follows:

"I think it was very positive because through games is always easier to learn. Especially the last session was the one that I found more interesting."

"Surely if these activities have done (in my case) in the accounting course would still have been more positive, as it would any fresher! It was a very interesting experience."

\section{Phase 3. Implementation during the course}

During the 2010-2011 academic year, specifically in the third quarter (April-June) was held the subject Introduction to Financial Accounting at the UPF. The objectives of this phase were:

- Check how the combination of lectures and dynamic games worked.

- Explore the students' opinion regarding the dynamics and its usefulness for learning.

The group had 90 students registered. The games were carried out in smaller seminar groups of 30 students.

Specifically, we spent the following questionnaire to the students after the experience:

Question 1. What do you think helped you to include dynamic participatory workshops? ( $1=$ not at all, $5=$ very much)

Question 2. How do you think would have helped you to have dynamic participatory instead of exercises in seminars? (One answer)

a) Greater involvement in the seminars

b) Improvement in the learning of the subject

c) Better interaction with peers

d) Improvement in the resolution of problems

Question 3. From everything you've learned throughout the course, what do you think are the main difficulties have an accounting department in a company? (open answer) 


\section{Results}

The results of the phase 3 were:

- Question 1. Students attending the course valued positively the dynamics. From a scale of 1 to 5 ( $1=$ none, 5 = very much), $66,7 \%$ rated the methodology with a 4 or a 5 .

- Question 2 dealt with the students' perception on how it this dynamics helped. Answers were mixed. In first place, students reported an improvement of the learning of the subject, $30.1 \%$ and second, greater involvement in the seminars, with $27.4 \%$. Third, students indicate that improves the relationship between the partners and, ultimately, improved problem solving. The results are shown in table 2.

\begin{tabular}{|l|c|}
\hline \multicolumn{1}{|c|}{ Results } & $\%$ \\
\hline Greater involvement in seminars & $27.4 \%$ \\
\hline Improved learning of the subject & $30.1 \%$ \\
\hline Better interaction with peers & $24.7 \%$ \\
\hline Improved problem solving & $17.8 \%$ \\
\hline
\end{tabular}

Table 2. Evaluation of the implementation phase

- In the qualitative analysis obtained from students' answers to Question 3, we observed a positive effect on the actual degree of integration of the content. This question was formulated to two groups: students from group A, who had participated in the dynamics and students from group $B$ that followed a traditional methodology. From the revision of the answers it emerged two patterns of answers: answers that followed strictly the title of the topics in the syllabus such as 'accrual accounting' or 'inventories', we called it 'Topic answers', and other answers that related topics or mentioned not included topics in the syllabus such as 'registering all the transactions' or 'balancing cash', we called it 'Mature answers'. As we can see in table 3, group A has a bigger 'mature' answer rate than group $B$, where the 'topic' answers exceed the percentage of group $A$.

\begin{tabular}{|l|c|c|c|c|}
\hline \multicolumn{1}{|c|}{ Answers } & Group A & \% & Group B & \% \\
\hline "Topic" answers & 12 & 18.18 & 19 & 33,33 \\
\hline "Mature" answers & 54 & 81.81 & 38 & 66,66 \\
\hline Total answers & 66 & 100 & 57 & 100 \\
\hline
\end{tabular}

Note: Group A=Students who have participated in the dynamics, Group $B=$ Students who have not participated in the dynamics.

Table 3. Qualitative analysis of the answers

Furthermore, we analyse the length of the answers of Question 3. Answers from students in group A where shorter and with similar length than in group B. Answers from group B were 
varied in lengths, either extremely short or extremely long. It might be that the question, more oriented to the professional application of knowledge, surprised the students in group $B$, which had not participated in the dynamic games.

Table 4 presents information about the average length of the answers. In this sense, it appears that in group A, average is practically equal (27.53) than in group B (28.26). To confirm that, in third column of table 4, is observed that, statistically, we can not reject the null hypothesis of equal averages at $5 \%$ of significance level. This is because the $P$ value $(0.899)$ is greater than the significance level of $5 \%$.

\begin{tabular}{|c|c|c|c|}
\hline Answers & Group A & Group B & Equality hypothesis (5\% significance) \\
\hline Average & 27,53 & 28,26 & Value P $=0.899$ Not Rejected \\
\hline
\end{tabular}

Table 4. F-Test of the average of the qualitative analysis

Table 5 presents information about deviations of the answers. In this sense, it appears that in group A, deviation is lower (26.46) than in group B (35.74). To confirm that, in third column of table 5 , is observed that, statistically, we can reject the null hypothesis of equal deviations at $5 \%$ of significance level. This is because the $P$ value $(0.02)$ is lower than the significance level of $5 \%$.

\begin{tabular}{|c|c|c|c|}
\hline Answers & Group A & Group B & Equality hypothesis (5\% significance) \\
\hline Deviation & 26,46 & 35,74 & Value $\mathrm{P}=0.02$ Rejected \\
\hline
\end{tabular}

Table 5. F-Test of the deviation of the qualitative analysis

Finally, after the analysis of the questionnaire we analyzed the final marks obtained by the students at the end of the course to see if there has been any impact on that. We compared between groups. Table 6 shows the final information. In each group there were around 90 to100 students. The group participating in the dynamic games was group 1, the rest followed a traditional methodology. Analyzing the results we can conclude: The marks obtained by group 1 are not too much higher, but we believe that the knowledge obtained has become more assimilated in that group than in the rest. The overall analysis, questionnaire and marks, allows us to make this conclusion. The final mark doesn't play any role; more learning doesn't meant directly higher qualifications. Higher learning means higher "skills" -as is required in the Bologna process-, but not higher marks.

\begin{tabular}{|c|c|c|c|c|c|c|}
\hline Answers & Group 1 & Group 2 & Group 3 & Group 4 & Group 5 & Group 6 \\
\hline Average & 5,798876 & 5,265116 & 6,472619 & 5,712941 & 6,206944 & 5,56044 \\
\hline Deviation & 1,513912 & 1,556902 & 1,701335 & 1,270057 & 2,062019 & 2,359326 \\
\hline
\end{tabular}

Table 6. Statistics of the marks 


\section{Conclusions}

The new approach to university teaching is moving towards a student-centered methodology. In this paper we presented the use of dynamic games as an additional learning tool to engage the students and improve participation in the subject Introduction to Financial Accounting. The games were introduced in only one group, that is around 90 students, (out of seven) and the subject assessment was identical for all students.

The subjective perception of the students participating in the dynamic games is that they improved their learning and felt greater involvement within the seminar group.

There are some contradictory results regarding the knowledge gained by the students. On one side, there was no impact on the final marks obtained by the students participating in the experiment in comparison with the others. On the other side, a further qualitative analyses to the responses provided by the students to several theoretical questions on the subject, showed a higher degree of content integration learning. The final assessment failed to capture this for the students that had participated in the dynamics.

After having run the experiment, we believe that the dynamics could be successfully applied to professional studies or even to secondary school, with a much reduced number of students.

During the course, the teachers were able to contrast that it requires a greater effort to organize group dynamics than to teach a master class and there is no actual compensation for the higher investment in the preparation of the dynamics and the level of attention required during the implementation.

Further research could explore the skills that the teacher must develop in order to manage this type of dynamic. Another potential line of research would be to link the use of dynamic games and Kolb's (1976) learning styles.

\section{References}

ANDERSON, J.A.; ADAMS, M (1992). Acknowledging the learning styles of diverse student populations: Implications for instructional design. In L.L. Border; N.V. Chism (Eds.). Teaching for diversity, 49: 19-33, San Francisco: Jossey-Bass.

CLAdELlas, R., CASTELlÓ, A., BADiA, M.M., CIRERA, M.C. (2013). Effects of the PowerPoint methodology on content learning. Intangible Capital, 9(1): 184-198.

COHEN, M. (1991). Making class participation a reality. Political Science and Politics, 24(4): 699-703. http://dx.doi.org/10.2307/419408 
GRAEML, F.R.; BAENA, V.; MIHAI YIANNAKI, S. (2010). La integración de diferentes campos del conocimiento en juegos de simulación empresarial. Revista de Docencia Universitaria, 8(2): 29-44.

GÓMEZ-RUIZ, L.M.; NARANJO-GIL, D. (2011). La competencia de trabajo en grupo: una propuesta de actividad y de evaluación. Revista de Docencia Universitaria, 9(2):193-211.

KOLB, D.A. (1976). On management and the learning process. California Management Review, 18(3): 21-31. http://dx.doi.org/10.2307/41164649

POZO, J.I.; PÉREZ ECHEVARRÍA, M.P. (2009). Psicología del aprendizaje universitario: La formación en competencias. Ediciones Morata, Madrid.

RODRÍGUEZ JIMÉNEZ, R.M.; TERRÓN, M.J.; GRACIA, P. (2010). Recursos creativos corporales y uso de la comunicación no-verbal para el desarrollo y evaluación de competencias genéricas en alumnos de grado. Revista de Docencia Universitaria, 8(1): 142-157.

SINCLAIR, B.; FERGUSON, K. (2009). Integrating Simulated Teaching/Learning Strategies in Undergraduate Nursing Education. International Journal of Nursing Education Scholarship 6(1). http://dx.doi.org/10.2202/1548-923X.1676

STEGEMANN, N.; SUTTON-BRADY, C. (2010). Putting Bling in the Classroom. Journal of Business and Economics Research, 8(1): 99-106.

TEJAdA PONCE, A.; PÉREZ MOROTE, R.; RAMÍREZ CÓRCOLES, Y.; TEJEdO ROMERO, F.; PONTONES ROSA, C. (2012). Análisis de la tasa de éxito en la asignatura de Contabilidad de Costes. Revista de Docencia Universitaria, 10(3): 347-377.

\section{(C) Intangible Capital, 2013 (www.intangiblecapital.org)}

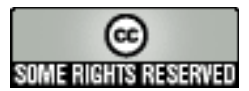

El artículo está con Reconocimiento-NoComercial 3.0 de Creative Commons. Puede copiarlo, distribuirlo y comunicarlo públicamente siempre que cite a su autor y a Intangible Capital. No lo utilice para fines comerciales. La licencia completa se puede consultar en http://creativecommons.org/licenses/by-nc/3.0/es/ 